\title{
OBSERVER ERROR AND VARIATION IN THE INTERPRETATION OF ELECTROCARDIOGRAMS IN AN EPIDEMIOLOGICAL STUDY OF CORONARY HEART DISEASE
}

\author{
BY \\ ROY M. ACHESON* \\ Department of Social Medicine, Moyne Institute, University of Dublin
}

It is widely accepted that the ECG is one of the most useful devices in the diagnosis of coronary heart disease, but it is important to establish whether, under the conditions of epidemiological research, the normal and abnormal ECG can be reliably and repeatedly distinguished from each other. The problem is in effect one of assessing the performance of an observer, and in doing this it is useful to differentiate between observer error and observer variation.

These two factors have been clearly distinguished and defined by Fletcher and Oldham (1959). "It is appropriate", they write, "to speak of observer error when, in the case of a simple classification into two categories of normal and abnormal, an observer places a case into one group and it can be shown, either by a majority opinion of a number of observers [or] by a subsequent re-examination by the same observer, ... that the case really belongs to the other group." They continue, in their definition of observer variation, "In the alternative and more frequent situation of a continuum where there are two or more categories and the observer is attempting to place a given case into the correct one, disagreement between observers, or in unrepeatability of the same observer may not stem entirely from error. . . . Subjects may be expected to fall on any part of the continuum, although possibly with greater frequency at one end or the other, and those near a boundary will inevitably be misclassified, more and more frequently the nearer they are to it, if there is any source of uncertainty at all."

By publishing a series of standard electrocardiographic tracings, the W.H.O. (1959) † attempted to define what does, and what does not constitute coronary heart disease. This does not, however, do away with observer variation, because in many cases

* Present address: London School of Hygiene and Tropical Medicine, Keppel Street, London, W.C.1:

t The electrocardiographic tracings, which are published as an annex to this otherwise excellent monograph, would appear to have been selected from clinical rather than epidemiological experience and are unlikely to prove helpful in survey work. opinions will differ as to whether the changes illustrated in the monograph are in fact present.

In a recent survey of the heart condition of a population samplet of over 220 elderly men-a preliminary report of which has already appeared (Acheson and Acheson, 1958)-the ECGs were all read by a single assessor. In order that some idea may be gained of how the frequency of heart disease (and in particular of coronary heart disease) in this sample compares with that in other samples or surveys, it is important that an estimate should be made of this assessor's observer error. In addition, it is of value in the final analysis of such a survey to know whether any pattern in an ECG leads to observer variation; whether, in Fletcher and Oldham's words, a specific pattern or patterns are "near the borderline".

\section{Material ANd Method}

The men were aged 65 to 85 and had been employed by a large Dublin industrial concern; full details of the selection of the sample and ECG technique are published elsewhere (Acheson and Acheson, 1958; Acheson, Hemmens, and Jessop, 1958). The tracings were made with a direct writing machine, and each tracing consisted of leads I, II, III, aVL, aVR, aVF, V1, V2, V3, V4, V5 and V6. Since it was impracticable to have all the tracings assessed by a number of different readers, it was decided to use a 25 per cent. sample. The cases were numbered, and the sample was chosen by taking a random number between 1 and 165-it proved to be 156-and then using 56 consecutive tracings numbered from 156 inclusive. They were all assessed from the intact original tracing by one observer (Assessment $\mathrm{A}_{1}$ ); then the author, who made no

¥ "Population Sample" in this series of studies has been used in the sense of an age-stratified random sample from a population of employees of a large industrial concern, so that the sample may be distinguished from those drawn entirely from old people's homes, hospitals, or geriatric clinics. No claim is made that the sample in question is representative of the old men of Dublin. 
assessments, cut the tracings up and mounted them on cards, so that two or three complexes were shown for each lead (Fig. 1). Then three other observers
(Assessments B, C, and D) read the tracings, and finally the first observer read them again (Assessment $A_{2}$ ). Thus, although four assessments were
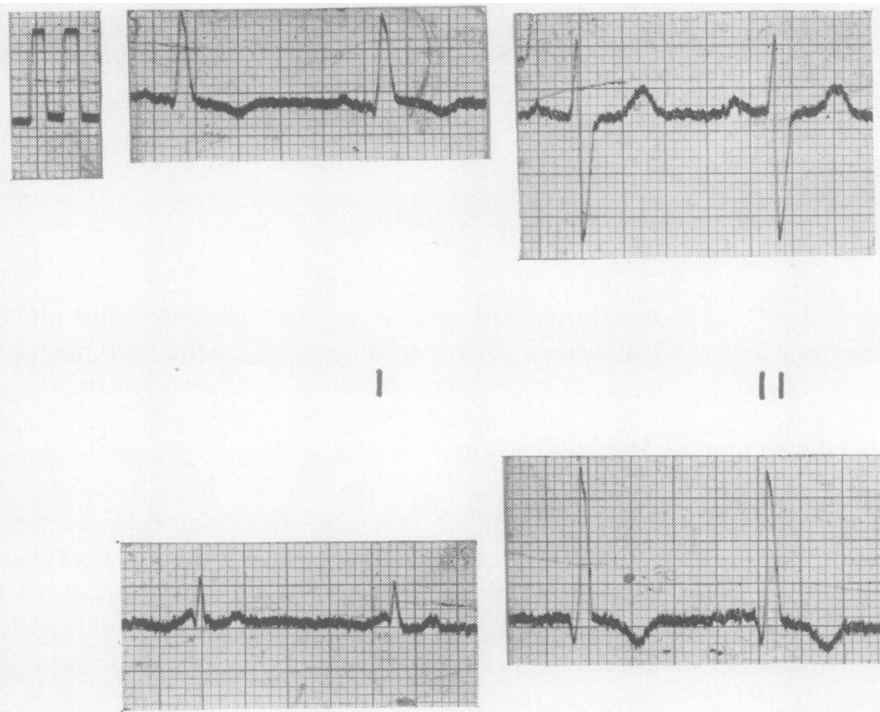

aVR
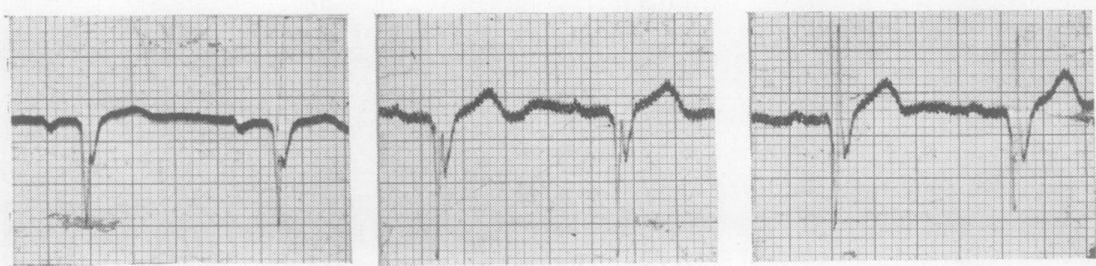

VI

V2

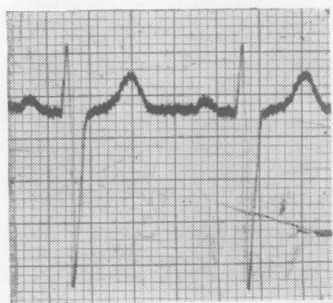

aVL

aVF

III

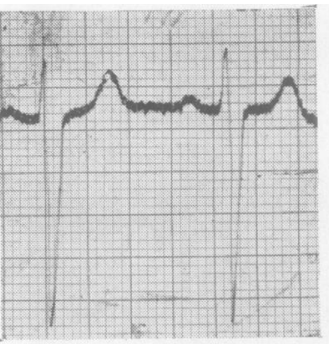

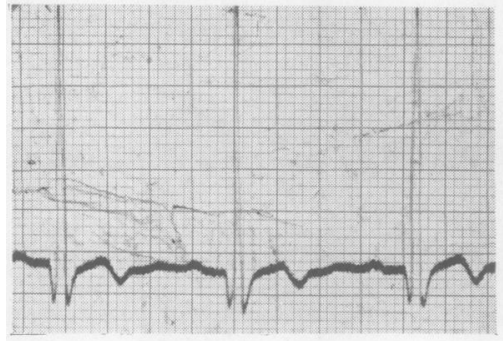

V 4

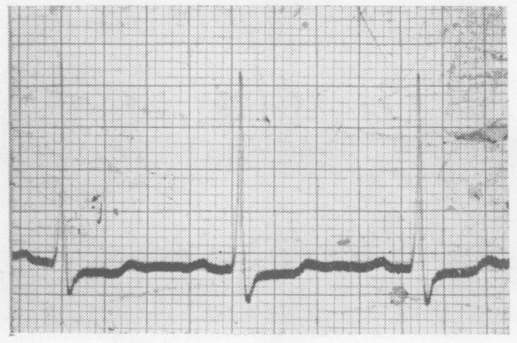

V5

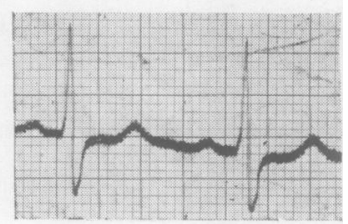

V 6

FIG. 1.-Specimen showing the form in which the ECGs were presented for all assessments (except in $A_{1}$ which was made from the intact tracing). The case shown is 213 , the only one in which it was agreed in all assessments that the changes were diagnostic of Myocardia Infarction. Two observers felt that Left Ventricular Hypertrophy was also present. 
made from the same mounted ECGs, Observer A's first assessment was made from more complete material; the possible significance of this unavoidable difference will be discussed further below. Of the four assessors, all of whom are members of the Royal College of Physicians, three (including Observer A), had special experience in electrocardiography, and the fourth was an epidemiologist particularly interested in diseases of the cardiovascular system.
Each of the observers was asked to fill in a prescribed form in respect of each tracing (Fig. 2). All the assessments were done independently and, with the exception of two who are acquainted, no observer was personally known to the others. The second occasion on which Observer A was asked to read the 56 tracings was more than 12 months after the first, and he had no record of his original interpretations. Furthermore, at the time of making his first interpretations he did not know that he would

GUINNESS' PENSIONERS SURVEY

INTERPRETATION OF ELECTROCARDIOGRAPHS

OBSERVER'S NAME OR CODE

CASE NO

NAME.

NUMBER OF TRACINGS

1. P WAVE

Normal

Other (specify)

2. P.R. INTERVAL (from Lead II)

Normal

Other (specify).

3. QRS COMPLEX

(a) QRS Interval (measured from Lead $V_{2}$ )

(b) Axis Deviation:

(c) Bundle Branch Block:

$\begin{array}{lll}\text { Nil } & \text { Left } & \text { Right } \\ \text { Nil } & \text { Left } & \text { Complete } \\ & \text { Right } & \text { Incomplete }\end{array}$

4. MYOCARDIAL INFARCTION

$Q$ Waves

Suggestive of Myocardial Infarction (specify leads)

Indicative of Myocardial Infarction (specify leads)

5. RS-T SEGMENT (excluding Myocardial Infarction)

Abnormally Elevated (specify leads).

Normal

Abnormally Depressed (specify leads)

6. T-WAVE (excluding Myocardial Infarction)

Normal

Absent (specify leads)

Inverted (specify leads)

7. DYSRHYTHMIAS
(a) None
(b) Atrial Fibrillation
(c) Tachycardia: Paroxysmal Supraventricular
(d) Bradycardia
Ventricular
(e) Ectopic Beats: Supraventricular
Ventricular
Interpolated
Multifocal

8. DIAGNOSIS OF ELECTROCARDIOGRAPHIC TRACING AT REST

PLEASE COMPLETE FORM BY RINGING APPROPRIATE WORD WHERE POSSIBLE

FIG. 2.-Prescribed form which the four observers were required to complete when they had interpreted the ECGs. 
be asked to read the tracings again.

The only information the observers were given about the old men from whom the tracings were made was age, blood pressure, and whether or not the subject had been taking digitalis-none of the sub-sample of 56 was, in fact, taking this drug.

\section{Results}

Comparison between the First AND SeCond ASSESSMENTS OF OBSERVER A

Observer A considered three of the 56 tracings to be unsuitable, either because they were incomplete or because they were technically imperfect and these were therefore discarded; on his first reading he classed 27 of the remaining 53 as normal (Group I), eight as having possible abnormalities (Group II), and eighteen as definitely abnormal (Group III). On his second reading he placed fewer tracings in Group II, with a consequent increase in the sizes of Groups I and III (Table I).

TABLE I

CLASSIFICATION OF 53 ECGS INTO THREE MAIN GROUPS BY OBSERVER A

\begin{tabular}{|c|c|c|c|c|}
\hline Assessment & .. $\quad$. & .. & $\mathbf{A}_{1}$ & $\mathbf{A}_{2}$ \\
\hline Group .. & $\begin{array}{l}\text { I. Normal } \\
\text { II. ? Abnorma } \\
\text { III. Abnormal }\end{array}$ & $\begin{array}{l}\ldots \\
\cdots\end{array}$ & $\begin{array}{r}27 \\
8 \\
18\end{array}$ & $\begin{array}{r}31 \\
2 \\
20\end{array}$ \\
\hline Total & $\ldots$ & $\ldots$ & 53 & 53 \\
\hline
\end{tabular}

Table II gives a more detailed analysis of the placing of the tracings in the three groups at the two assessments. It will be seen that, apart from one tracing classed as normal at $A_{1}$ and abnormal at $A_{2}$, and another moved from Group III to Group II at the second reading, all the differences are concerned with the eight tracings placed in Group II at Assessment $\mathbf{A}_{1}$.

TABLE II

GROUPING AT $A_{2}$ OF ASSESSMENTS MADE AT $A_{1}$

\begin{tabular}{|c|c|c|c|c|}
\hline \multirow{2}{*}{ Grouping at $\mathbf{A}_{1}$} & \multicolumn{3}{|c|}{ Grouping at $A_{2}$} & \multirow{2}{*}{ Total } \\
\hline & I & II & III & \\
\hline I & 26 & 0 & 1 & 27 \\
\hline II & 5 & 1 & 2 & 8 \\
\hline III & 0 & 1 & 17 & 18 \\
\hline $\begin{array}{lll}\text { Total } \ldots & \ldots\end{array}$ & 31 & 2 & 20 & 53 \\
\hline
\end{tabular}

Comparison between the Assessments of ObServer A AND THOSE OF OBSERVERS B, C, AND D

The fairest way of comparing the performance of Observer A with those of B, C, and D is in terms of Assessment $A_{2}$, because this was carried out from mounted ECGs, whereas Assessment $A_{1}$ had been carried out from the original unmounted strips. Table III shows how the grouping of the other observers compared with that of $\mathrm{A}_{2}$; by reading this Table from the top left corner diagonally to the bottom right corner, it is evident that there was agreement with Assessment $A_{2}$ on 134 (84 per cent.) occasions.

TABLE III

COMPARISON BETWEEN GROUPING AT A, AND OTHER ASSESSMENTS OF MOUNTED ECGS

\begin{tabular}{|c|c|c|c|c|}
\hline \multirow{2}{*}{ Grouping at $A_{2}$} & \multicolumn{3}{|c|}{ Grouping at $B, C$, and D } & \multirow{2}{*}{ Total } \\
\hline & I & II & III & \\
\hline $\mathbf{I}$ & 84 & 3 & 6 & 93 \\
\hline II & 2 & 2 & 2 & 6 \\
\hline III & $\overline{6}$ & 6 & 48 & 60 \\
\hline Total .. & 92 & 11 & 56 & 159 \\
\hline
\end{tabular}

In thirteen (8 per cent.) assessments an ECG was placed in the group next to that designated at Assessment $\mathbf{A}_{\mathbf{2}}$; these are called first degree disagreements. Twelve (8 per cent.) of the subsequent assessments were second degree disagreements, that is, a tracing classified as Group $I$ at $\mathbf{A}_{2}$ was classified subsequently as Group III or vice versa. This analysis is shown in Table IV, which also gives a similar summary of the differences shown between $A_{1}$ and $A_{2}$ in Table II, and of all subsequent assessments compared with $A_{1}$.

TABLE IV

DEGREE OF DISAGREEMENT IN GROUPING $A_{2}$ WITH $A_{1}$, $B, C, A N D$ D WITH A AND ALL SUBSEQUENT ASSESSMENTS WITH $A_{1}$

\begin{tabular}{|c|c|c|c|c|c|c|c|}
\hline \multirow{2}{*}{ Comparison } & \multirow{2}{*}{. } & \multicolumn{2}{|c|}{$A_{2}$ with $A_{1}$} & \multicolumn{2}{|c|}{$\begin{array}{c}B, C \text {, and } D \\
\text { with } A_{2}\end{array}$} & \multicolumn{2}{|c|}{$\begin{array}{c}\mathbf{A}_{\mathbf{2}}, \mathbf{B}, \mathbf{C} \text {, and } \\
\mathbf{D} \text { with } \mathbf{A}_{\mathbf{1}}\end{array}$} \\
\hline & & No. & $\begin{array}{l}\text { Per } \\
\text { cent. }\end{array}$ & No. & $\begin{array}{c}\text { Per } \\
\text { cent. }\end{array}$ & No. & $\begin{array}{l}\text { Per } \\
\text { cent. }\end{array}$ \\
\hline Agreement & . & 44 & 83 & 134 & 84 & 163 & 77 \\
\hline \multirow{2}{*}{$\begin{array}{c}\text { Disagree- } \\
\text { ment }\end{array}$} & $\begin{array}{c}\text { First } \\
\text { Degree }\end{array}$ & 8 & 15 & 13 & 8 & 42 & 20 \\
\hline & $\begin{array}{c}\text { Second } \\
\text { Degree }\end{array}$ & 1 & 2 & 12 & 8 & 7 & 3 \\
\hline Totals & .. & 53 & 100 & 159 & 100 & 212 & 100 \\
\hline
\end{tabular}

To summarize so far, when Observer $A$ is tested for his ability to repeat his own performance, the most striking difference between his two sets of assessments is that the second is more positive, inasmuch as it has fewer Group II classifications than the first. This may be because the process of mounting the tracings left him with selected complexes to study when he made his second series of assessments, a suggestion which is to some extent borne out by the fact that the frequency of Group II classifications 
in assessments $\mathrm{B}, \mathrm{C}$, and $\mathrm{D}$ is more similar to the pattern of $A_{2}$ than any of the four are to that of $A_{1}$. The effect of this increased positivity, however, is to make the number of second degree disagreements higher when $A_{2}$ is compared with the other three observers than when it is compared with $A_{1}$, or when $A_{1}$ is compared with all four assessments (Table IV).

The number of disagreements with the actual diagnosis as opposed to the grouping reached at Assessment $A_{1}$ are shown in Table $V$, where it can be seen that there was some measure of disagreement in respect of 21 tracings, six of which were originally placed in Group I, eight in Group II, and seven in Group III. Three of the five in Group II which were considered to be normal at Assessment $\mathrm{A}_{2}$ were also grouped as normal at all subsequent assessments; because all observers were unanimous about these three ECGs in their mounted form, they will not be considered further, nor will three placed in Group $I$ at Assessment $A_{1}$, but grouped as "? abnormal" by just one other observer. The remaining fifteen of the 21 ECGs were subject to a wider margin of disagreement and are therefore worthy of a more detailed discussion.

TABLE V

OCCASIONS ON WHICH ASSESSMENTS A, B, C, AND D DISAGREED WITH THE PRECISE DIAGNŐSIS MADE AT ASSESSMENT $A_{1}$

\begin{tabular}{|c|c|c|c|c|c|c|}
\hline \multirow{2}{*}{ Group } & \multicolumn{6}{|c|}{ Number of Disagreements on Each ECG } \\
\hline & None & One & Two & Three & Four & Totals \\
\hline $\begin{array}{r}\text { I } \\
\text { III }\end{array}$ & $\frac{21}{11}$ & $\begin{array}{l}5 \\
2+ \\
-\end{array}$ & $\begin{array}{l}1 \\
2 \\
2^{*}\end{array}$ & $\overline{1}$ & $\begin{array}{l}\overline{3} \\
2^{*}\end{array}$ & $\begin{array}{r}27 \\
8 \\
18\end{array}$ \\
\hline Total ECGs & 32 & 7 & 5 & 4 & 5 & 53 \\
\hline
\end{tabular}

* One case in each group marked thus was diagnosed by $A_{1}$ "Lef Ventricular Hypertrophy or Myocardial Ischaemia".

t One case in this group was diagnosed by $A_{1}$ "? Left Ventricular Hypertrophy ? Myocardial Ischaemia".
FURTHER DESCRIPTION OF ECGS GIVING RISE tO A WIDE DIFFERENCE OF OPINION

In this section the fifteen "difficult" ECGs, together with the diagnoses at all five assessments, will be shown; for the sake of simplicity the grouping made at Assessment $A_{1}$ will be used as a basis for classification.

Group I.-The three tracings giving rise to definite disagreement in Group I are shown (Fig. 3, overleaf, pp. 104-106) together with the diagnoses offered at all assessments (Table VI). It will be seen that only one observer doubted the normality of two of the tracings - but that two considered the third tracing (189) abnormal, one of these being Observer A himself. It is worth noting that the suggested abnormalities were Left Ventricular Hypertrophy (on three occasions) and Infarct (once).

Group II.-The eight cases in which Observer A was uncertain whether the tracing was abnormal at his first reading were those about which the difference of opinion was greatest. In three (two ? Infarction and one ? Left Ventricular Hypertrophy), the possibility of abnormality was not raised in any of the four subsequent assessments. The other five cases are shown in Fig. 4 (overleaf, pp. 107-111), and the various interpretations are given in Table VII (overleaf, p. 112). One case (175) presents a special difficulty because the subject suffered from a gross Parkinsonian muscular tremor. In the others the chief difficulty lay in deciding whether the tracing was in fact normal $(158,190,215)$ and in making a distinction between Left Ventricular Hypertrophy and Myocardial Ischaemia (190 and 193).

Group III.-Eighteen tracings were declared abnormal by Observer A on his first reading, and in eleven there was a wide measure of agreement as to the nature of the abnormality. These were diagnosed by him as Left Ventricular Hypertrophy (five), Myocardial Ischaemia (one), Myocardial Ischaemia or Left Ventricular Hypertrophy (one), Atrial

TABLE VI*

INTERPRETATIONS OF THREE GROUP I ECGS ABOUT WHICH THERE WAS SECOND DEGREE DISAGREEMENT AS TO GROUPING (SEE FIG. 3)

\begin{tabular}{c|c|c|c|c|c|c|c|c}
\hline \multirow{2}{*}{ Case No. } & \multirow{2}{*}{ Age (yrs) } & \multicolumn{2}{|c|}{ Blood Pressure } & \multicolumn{5}{|c|}{ Interpretations of Observers } \\
\cline { 2 - 7 } & Systolic & Diastolic & $A_{1}$ & $A_{2}$ & B & \multicolumn{2}{c}{ C } & D \\
\hline 167 & 72 & 150 & 85 & Normal & Normal & $\begin{array}{c}\text { Left Ventricular } \\
\text { Hypertrophy }\end{array}$ & Normal & Normal \\
\hline 189 & 72 & 210 & 120 & Normal & Old Infarct & Normal & $\begin{array}{c}\text { Left Ventricular } \\
\text { Hypertrophy }\end{array}$ & Normal \\
\hline 207 & 70 & 180 & 105 & Normal & Normal & Normal & $\begin{array}{c}\text { Left Ventricular } \\
\text { Hypertrophy }\end{array}$ & Normal \\
\hline
\end{tabular}

* In Tables VI to IX inclusive the observer's original wording has been used wherever possible. 
CASE 167
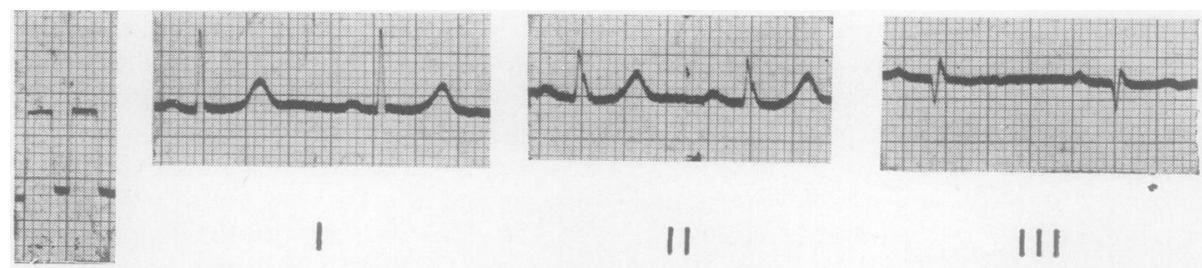

II

III
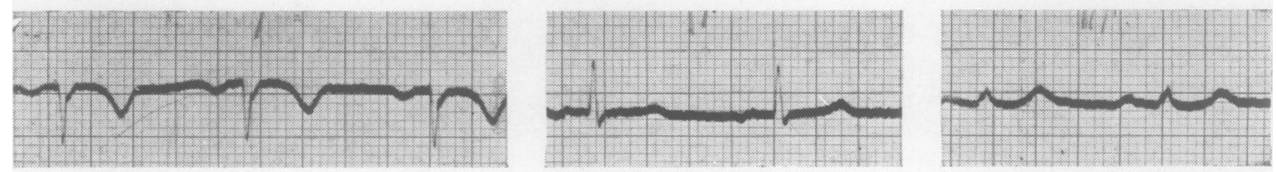

a VR

aVL

aVF
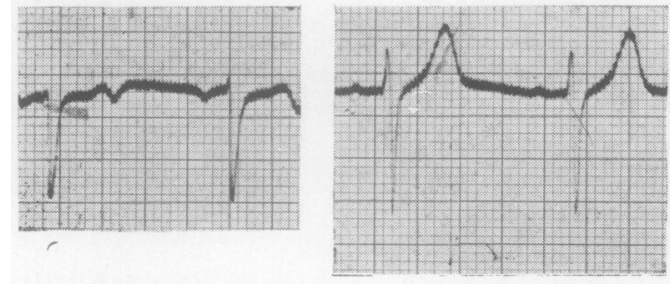

V J

V2

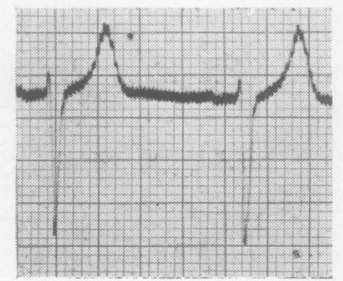

V3

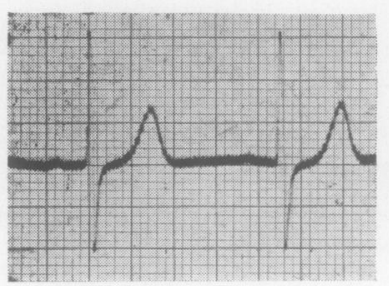

V4

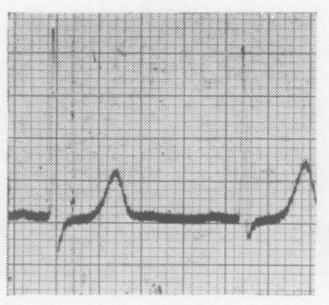

V5

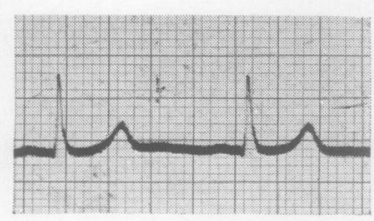

V6

Fig. 3.-Three ECGs which were placed in Group I at Assessment $A_{1}$ and gave rise to second degree disagreement in grouping (see also Table VI). 
CASE 189

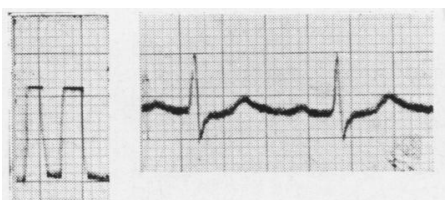

।

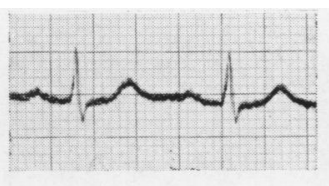

II

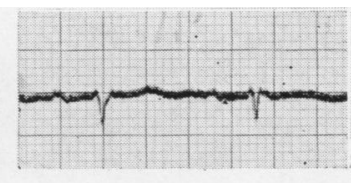

III

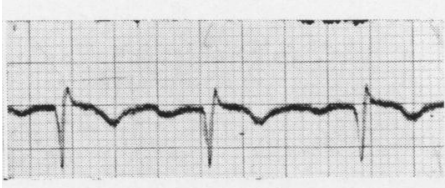

QVR

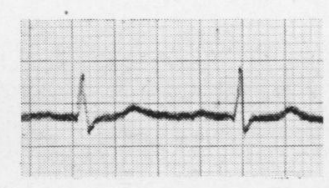

QVL

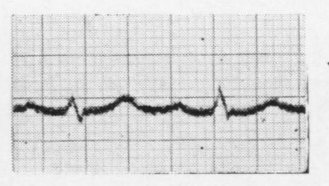

aVF

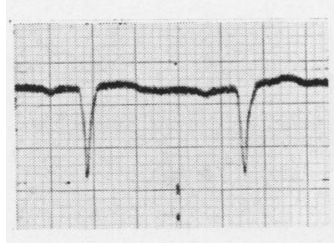

VI

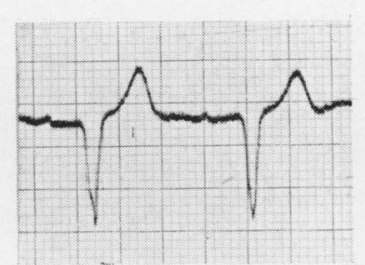

$\vee 2$

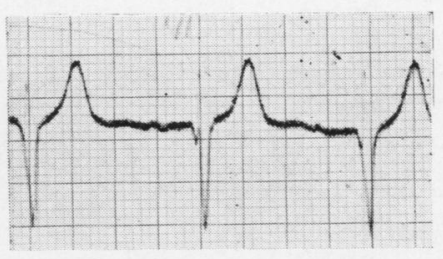

V 3

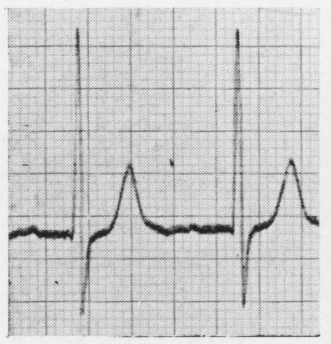

v4

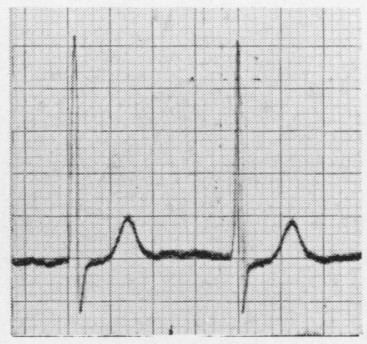

V5

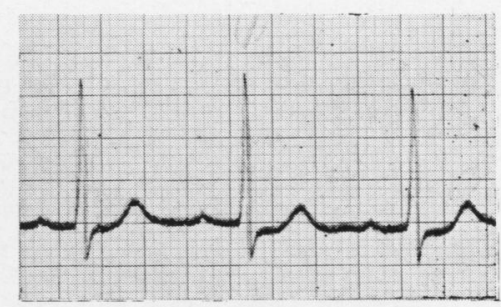

V6

FIG. 3 (continued). 
CASE 207

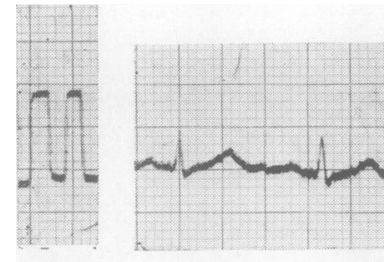

I

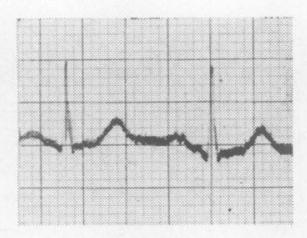

II

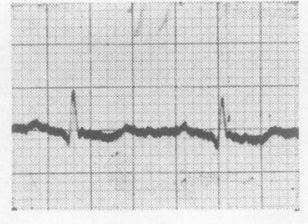

III

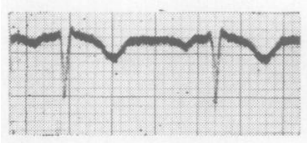

aVR

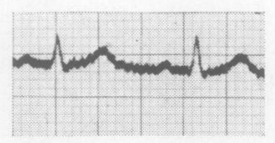

aVL

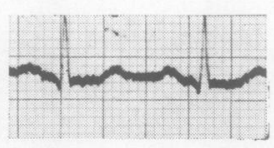

aVF
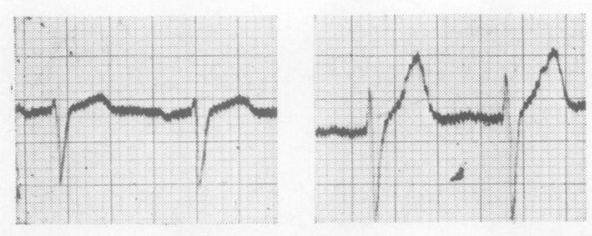

V I

V2

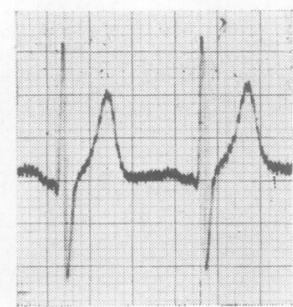

V3

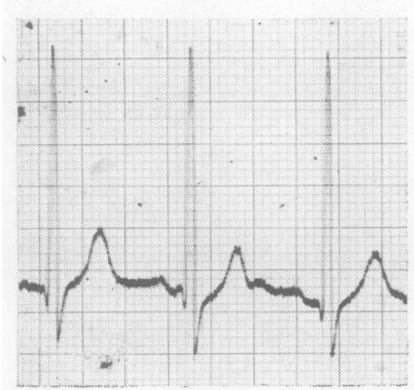

V4
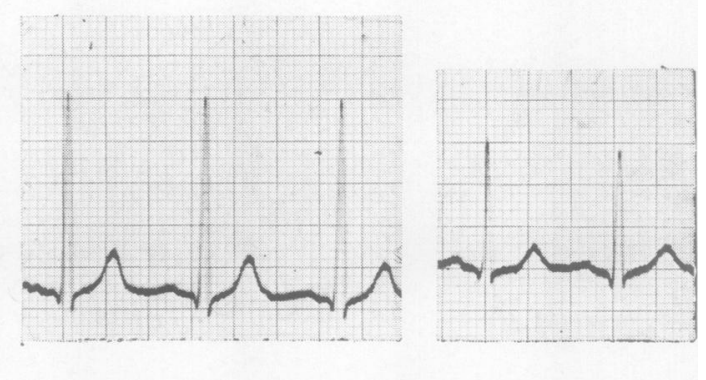

V 5

FIG. 3 (continued). 
CASE 158
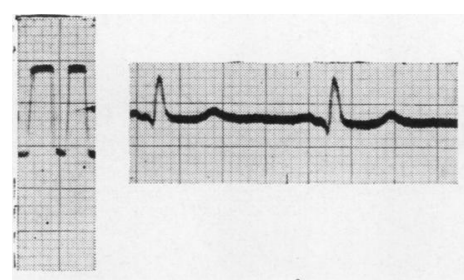

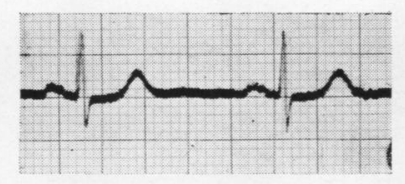

II

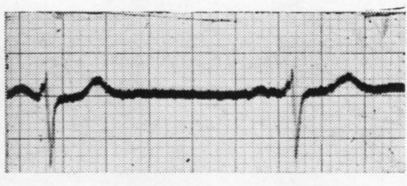

III

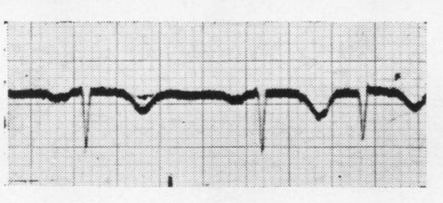

$a \vee R$

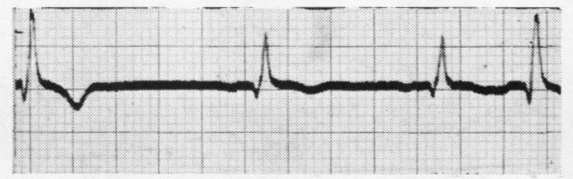

QVL

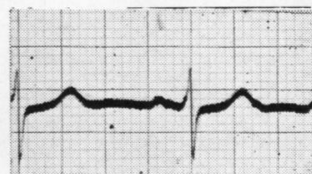

aVF

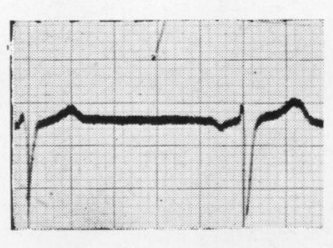

VI

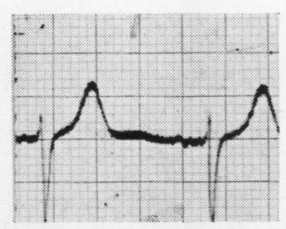

V 2

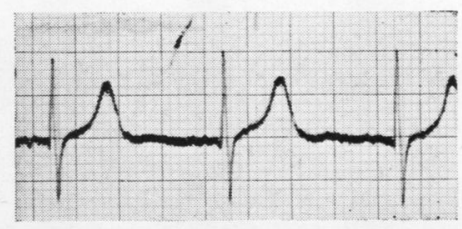

V 3
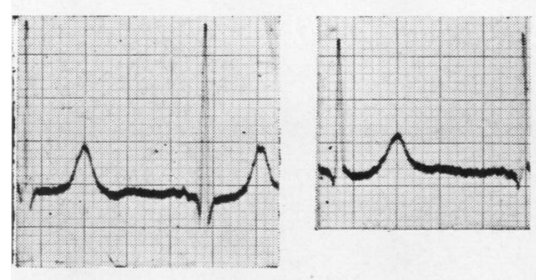

V 5

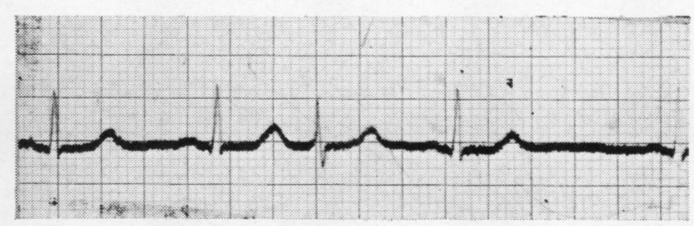

V 6

FIG. 4.-Five ECGs in Group II which gave rise to disagreement in grouping (see also Table VII). 


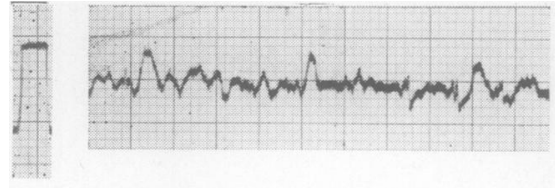

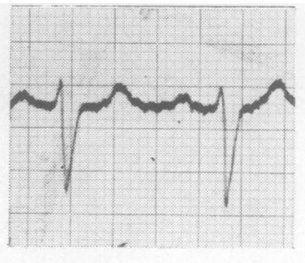

II

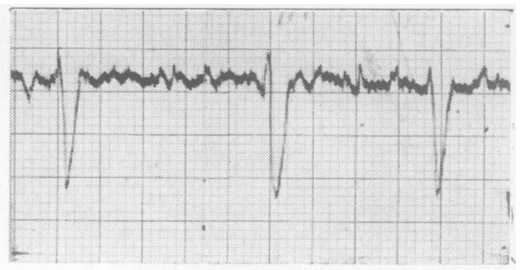

III

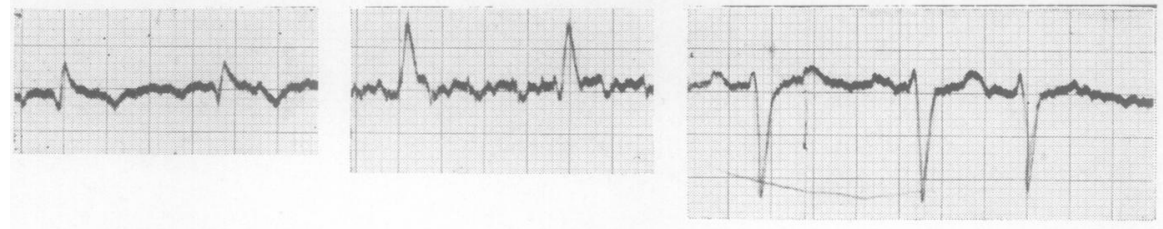

QVR

QVL

aVF

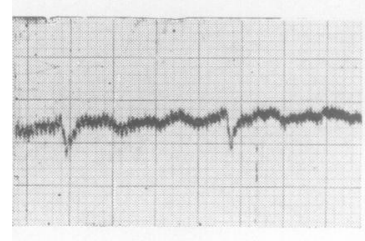

VI

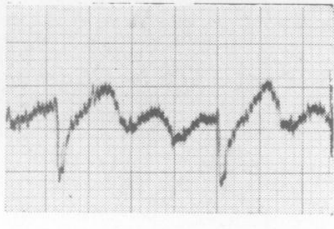

V2

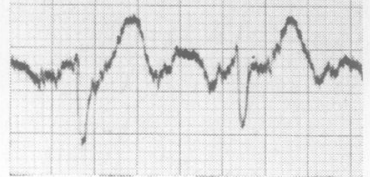

V3

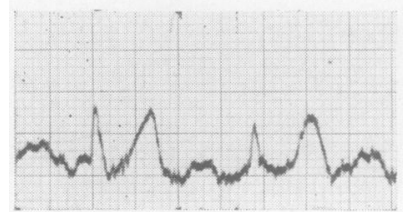

V4

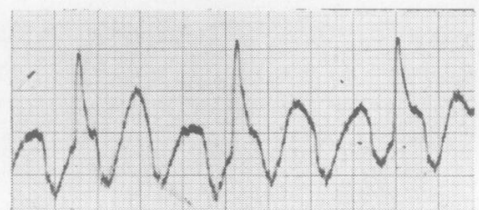

V 5

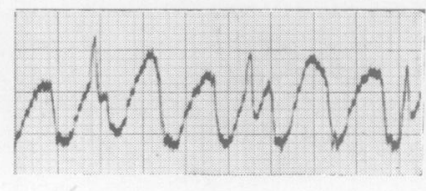

V6

FIG. 4 (continued). 
CASE 190

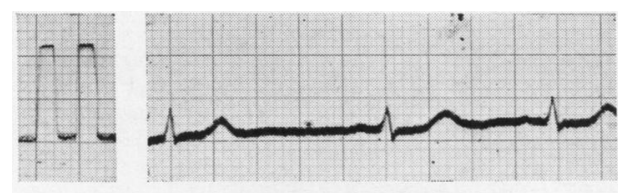

I

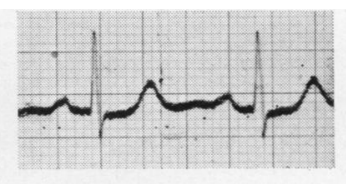

II

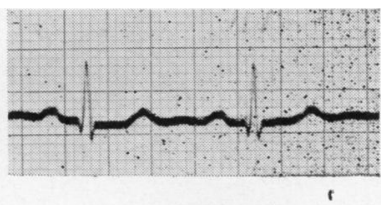

III

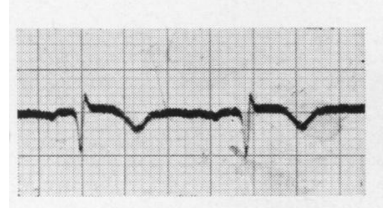

QVR

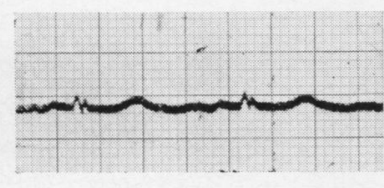

QVL

aV F
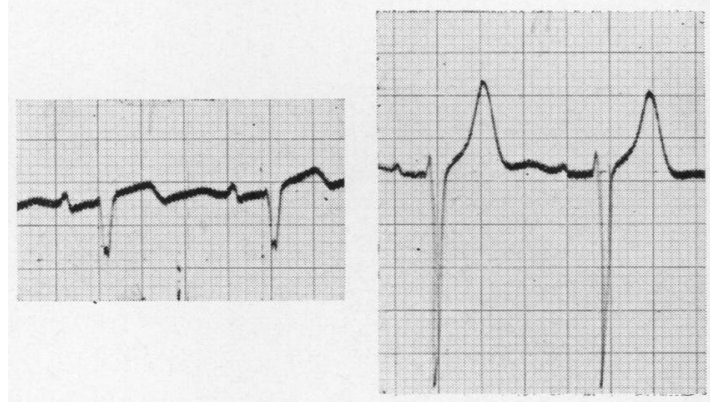

V 2

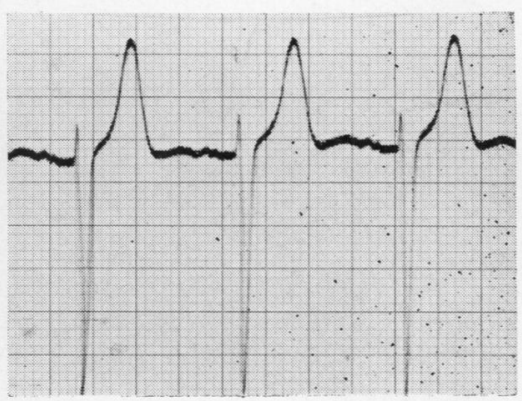

V

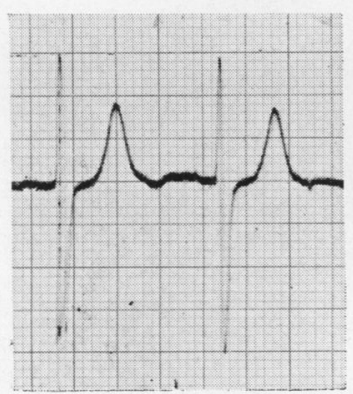

V4
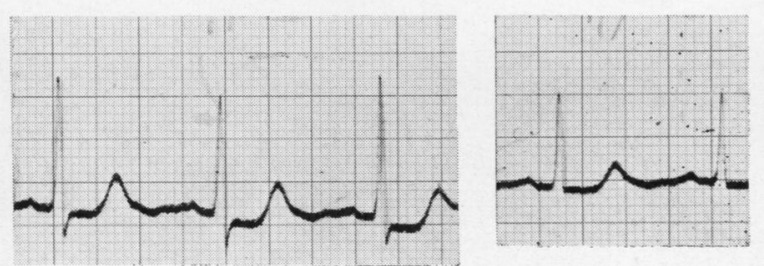

V 5

V6

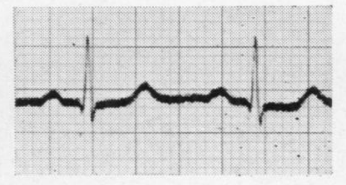

v3

FIG. 4 (continued). 
CASE 193

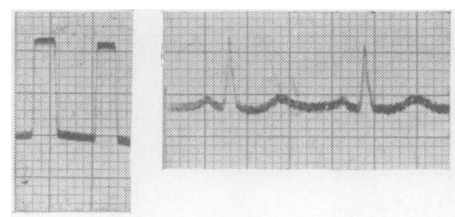

I

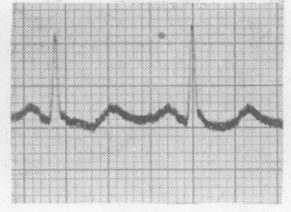

II

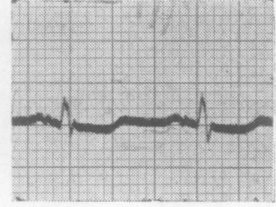

III

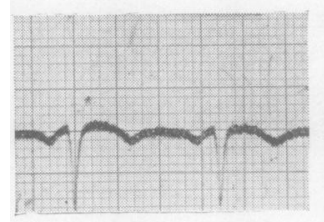

aVR

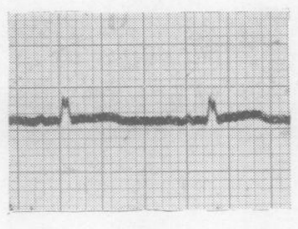

AVL

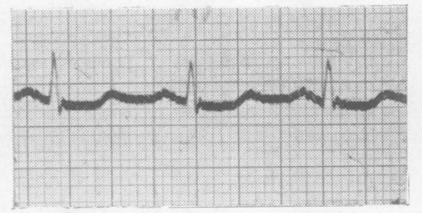

QVF
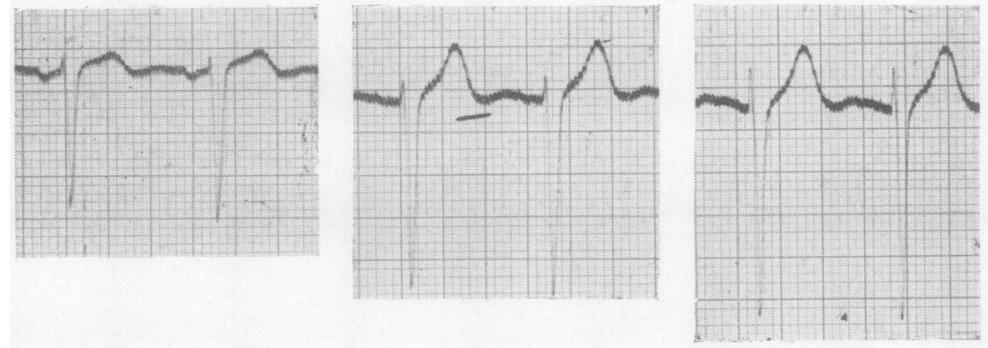

V3

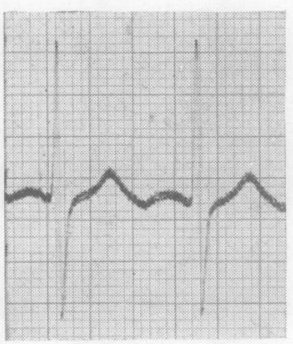

V4

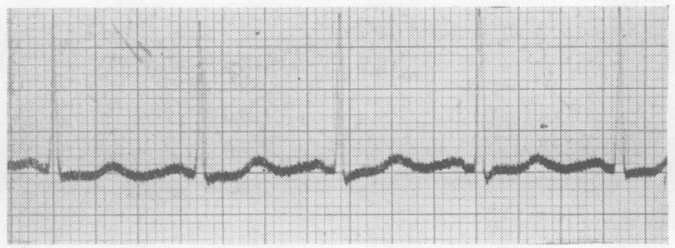

V 5

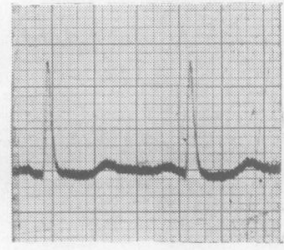

V6

Fig. 4 (continued). 
CASE 215
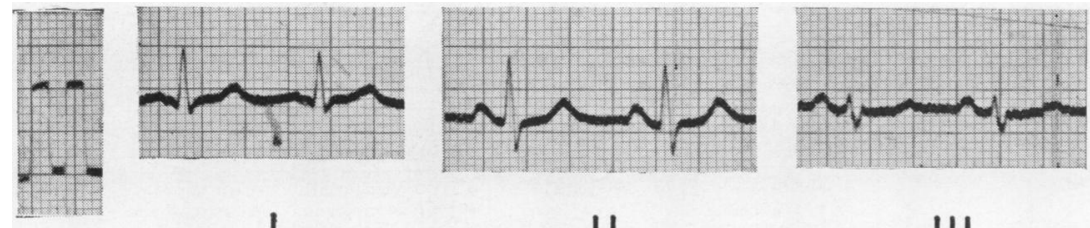

I

II

III

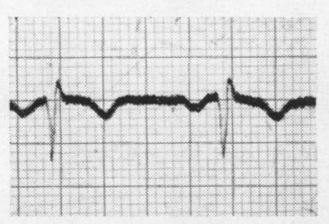

aVR

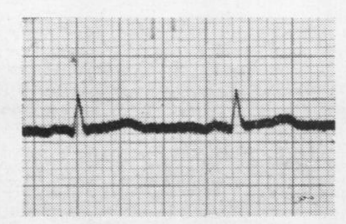

aVL

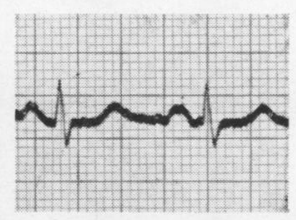

aVF
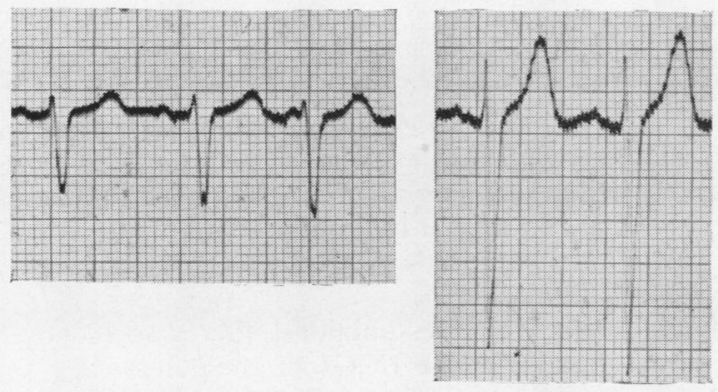

VI

$\vee 2$

V3
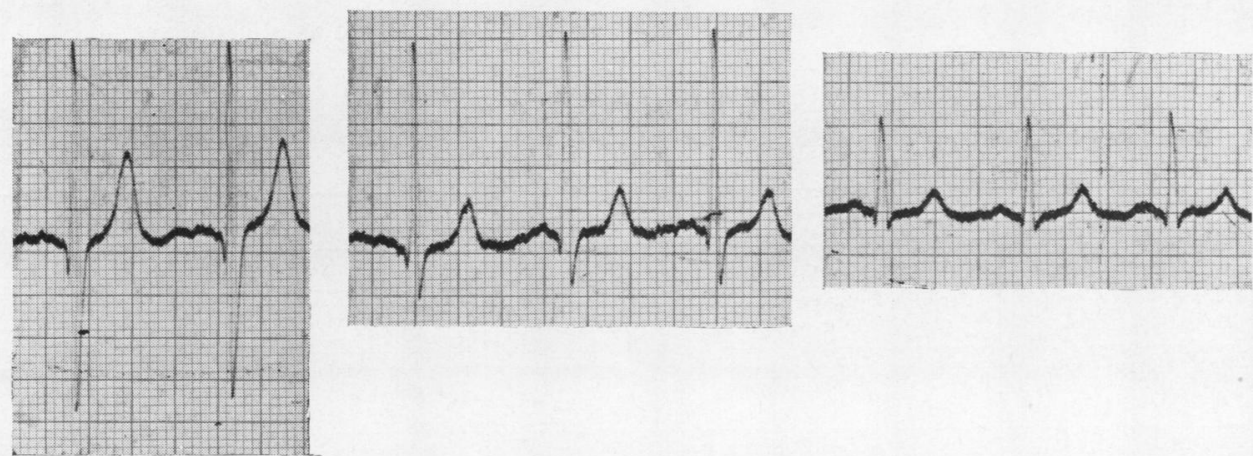

V 5

FIG. 4 (continued). 
TABLE VII

INTERPRETATIONS OF FIVE GROUP II ECGs (SEE FIG. 4)

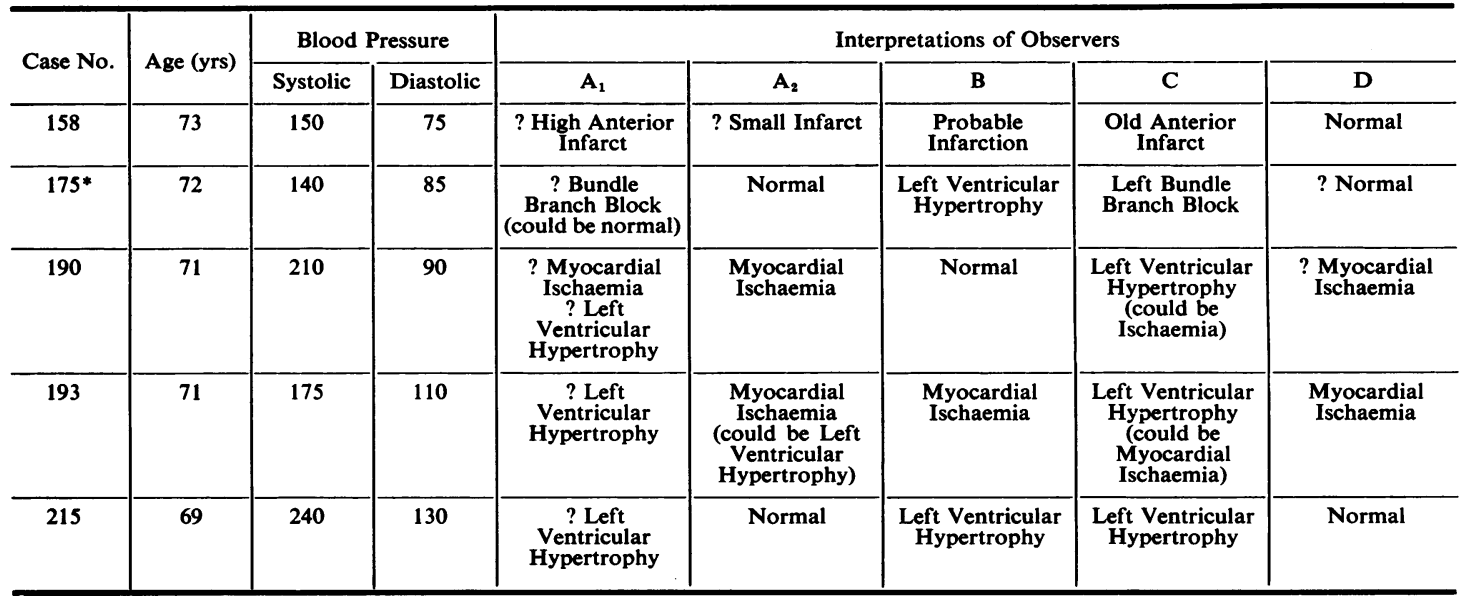

- Case 175 had a severe Parkinsonian tremor (see Fig. 4).

Fibrillation (three), and Myocardial Infarction (one). In four of the five cases with Left Ventricular Hypertrophy, this was considered to be the most likely diagnosis at all the four succeeding assessments; in the fifth case, Ischaemia was put forward as more likely at all the four later assessments. In the case considered at Assessment $\mathbf{A}_{1}$ to be "Myocardial Ischaemia or Left Ventricular Hypertrophy", the same diagnosis was made at $\mathrm{A}_{2}$; at $\mathrm{B}$ and $\mathrm{C}$ the diagnosis was "Ischaemia", and at $\mathrm{D}$ it was "Ischaemia ? Infarction". Similarly, in the single case of Myocardial Ischaemia, the possible alternative diagnosis of "? Left Ventricular Hypertrophy" put forward by Observer A at his first assessment, was repeated at $\mathrm{A}_{2}$ and also put forward by Observer B.

All the observers agreed that there was Atrial Fibrillation in three cases, and that this was un- complicated in one of the three. It was agreed by all that there was a further complication in the other two cases; in Case 185 this was thought to be Left Ventricular Hypertrophy or Myocardial Ischaemia, and in Case 159 an Infarct by A (both assessments) and C, or Ischaemia by B and D. In the one case (213) in which all observers agreed on the diagnosis of Myocardial Infarction, $A_{1}, B$, and $C$ thought that Left Ventricular Hypertrophy was also present (Fig. 1).

In four cases opinions differed considerably as to diagnosis; the ECGs of these cases are shown in Fig. 5 (opposite, pp. 113-116), and the interpretation in Table VIII. In all of them the original diagnosis $\left(\mathrm{A}_{1}\right)$ was Left Ventricular Hypertrophy; in two cases this was also suggested by another observer, and in all cases Myocardial Ischaemia and Myocardial Infarction were offered as alternatives.

TABLE VIII

INTERPRETATIONS OF FOUR ECGS WHICH NO OBSERVER CONSIDERED NORMAL BUT ABOUT WHICH THERE WAS DISAGREEMENT AS TO DIAGNOSIS (SEE FIG. 5)

\begin{tabular}{|c|c|c|c|c|c|c|c|c|}
\hline \multirow{2}{*}{ Case No. } & \multirow{2}{*}{ Age (yrs) } & \multicolumn{2}{|c|}{ Blood Pressure } & \multicolumn{5}{|c|}{ Interpretations of Observers } \\
\hline & & Systolic & Diastolic & $\overline{A_{1}}$ & $\overline{A_{2}}$ & B & $\mathbf{C}$ & D \\
\hline 157 & 70 & 170 & 105 & $\begin{array}{l}\text { Left Ventricular } \\
\text { Hypertrophy }\end{array}$ & $\begin{array}{l}\text { Left Ventricular } \\
\text { Hypertrophy }\end{array}$ & $\begin{array}{l}\text { Probable } \\
\text { Infarct }\end{array}$ & Ischaemia & ? Ischaemia \\
\hline 181 & 78 & 150 & 95 & $\begin{array}{l}\text { Left Ventricular } \\
\text { Hypertrophy }\end{array}$ & ? Ischaemia & $\begin{array}{l}\text { Left Ventricular } \\
\text { Hypertrophy } \\
\text { ? Infarct }\end{array}$ & $\begin{array}{c}\text { Old Anterior } \\
\text { Infarct }\end{array}$ & ? Ischaemia \\
\hline 183 & 71 & 175 & 85 & $\begin{array}{l}\text { Left Ventricular } \\
\text { Hypertrophy }\end{array}$ & $\begin{array}{c}\text { Ischaemia } \\
\text { ? Old Infarct }\end{array}$ & Old Infarct & Ischaemia & $\begin{array}{l}\text { Ischaemia } \\
\text { ? Old Infarct }\end{array}$ \\
\hline 209 & 69 & 170 & 100 & $\begin{array}{l}\text { Left Ventricular } \\
\text { Hypertrophy }\end{array}$ & $\begin{array}{l}\text { Left Ventricular } \\
\text { Hypertrophy } \\
\text { or Ischaemia }\end{array}$ & $\begin{array}{l}\text { Gross Left } \\
\text { Ventricular } \\
\text { Hypertrophy }\end{array}$ & $\begin{array}{l}\text { Anterior } \\
\text { Infarct or } \\
\text { Ischaemia }\end{array}$ & Ischaemia \\
\hline
\end{tabular}


CASE 157

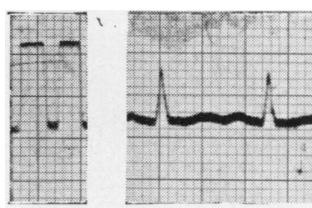

I

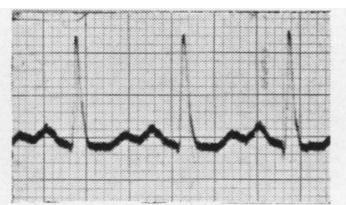

II

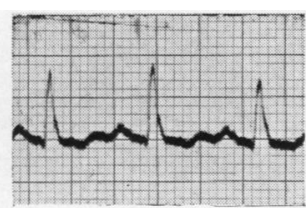

III

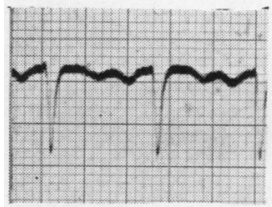

aVR

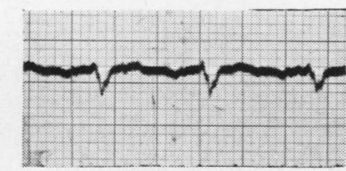

QVL

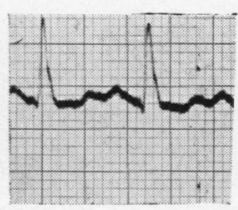

aVF

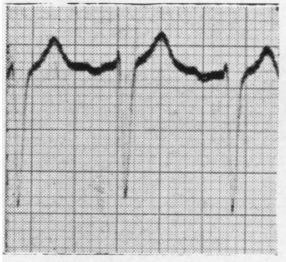

V I

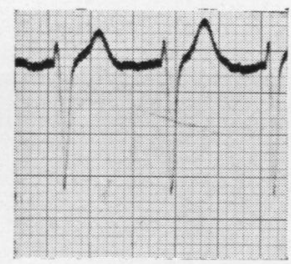

V2

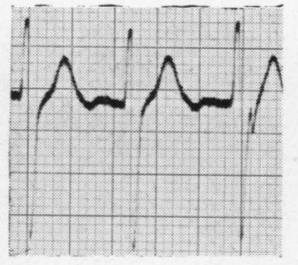

V 3

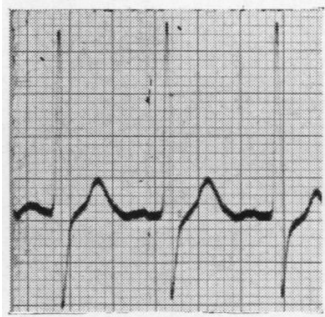

V4

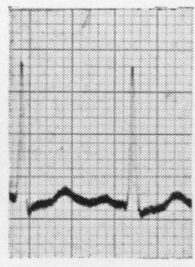

V 5

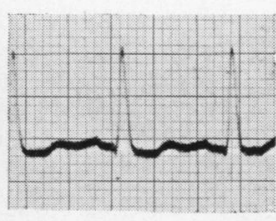

V 6

Fig. 5.-Four ECGs in Group III about which there was disagreement in precise diagnosis (see also Table VIII). 
CASE 181
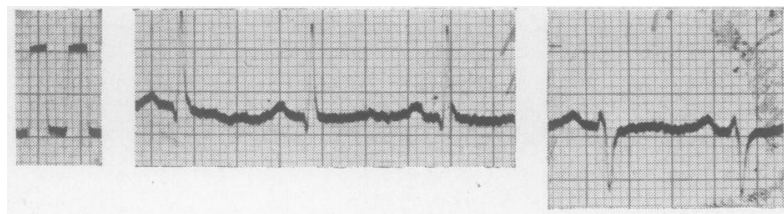

I

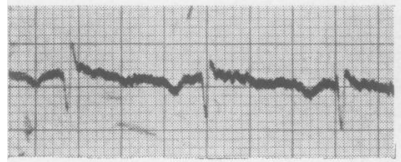

aVR

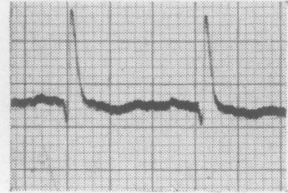

aVL

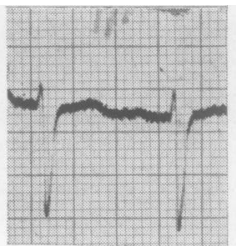

III

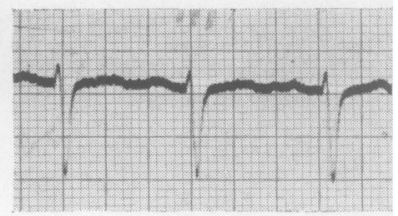

aVF
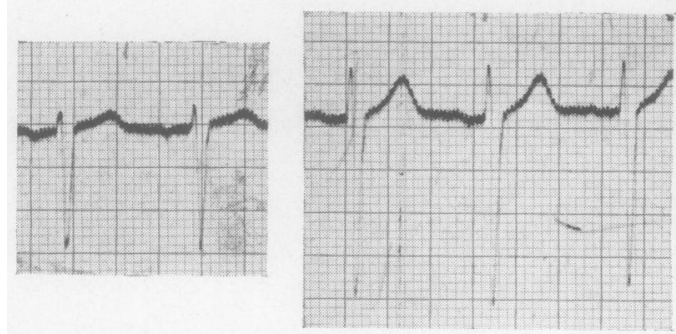

V I

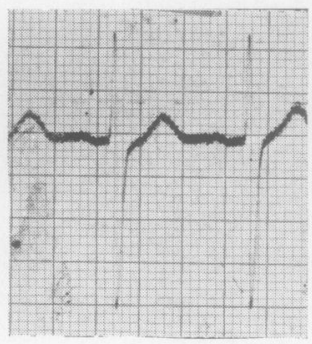

V 3
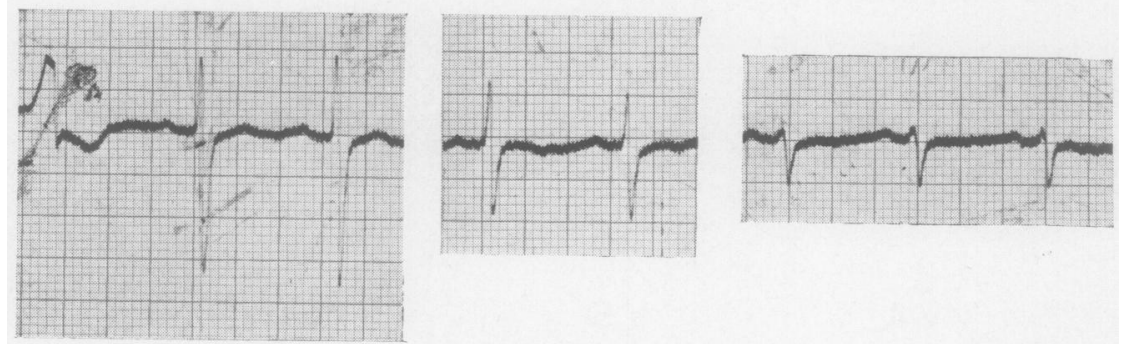

V4

V 5

V 6

FIG. 5 (continued). 
CASE 183
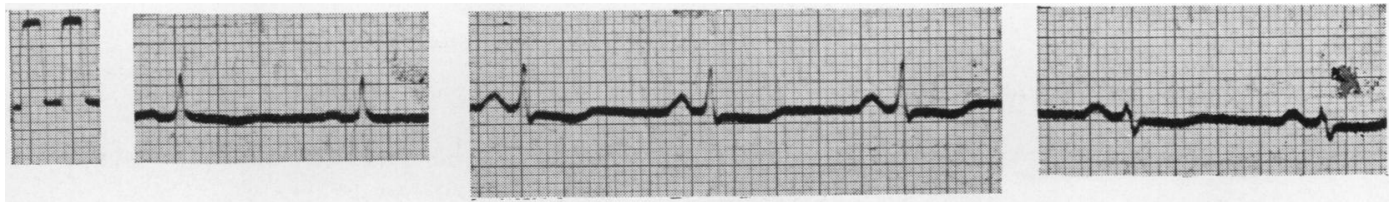

I

II

III

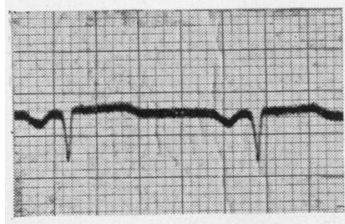

a VR

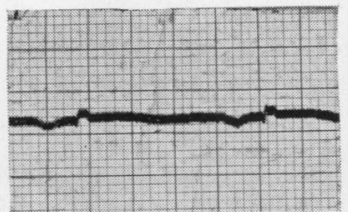

QVL

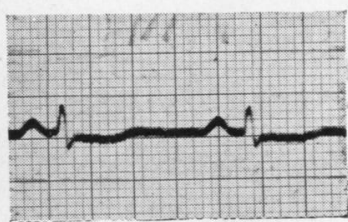

$a \vee F$

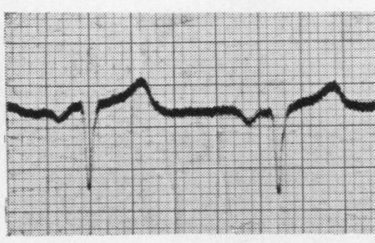

V I

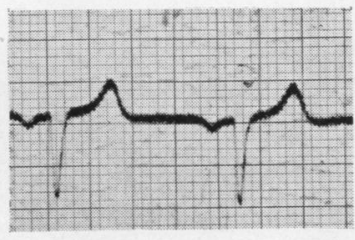

V 2

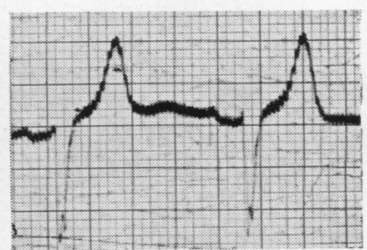

V 3

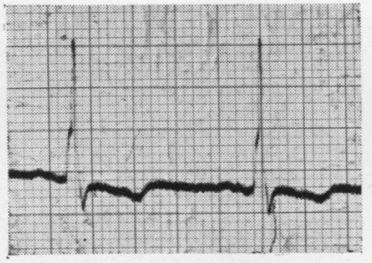

v 4

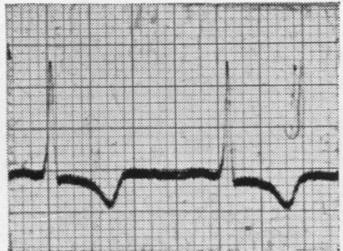

V 5

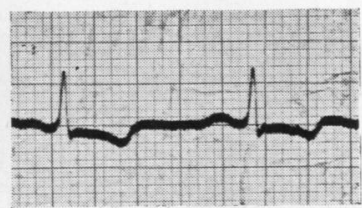

V 6

Fig. 5 (continued). 
CASE 209
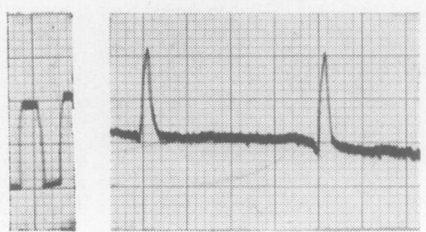

I

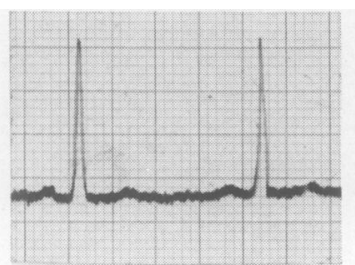

II

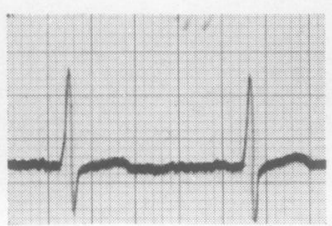

III

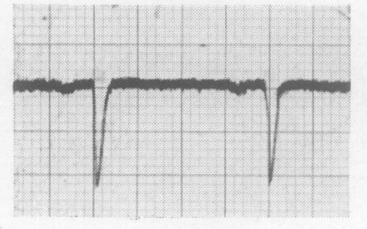

aVR

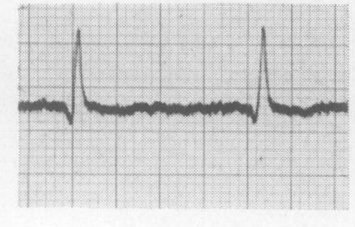

aVL

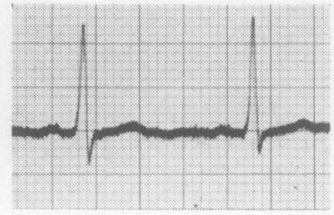

a VF

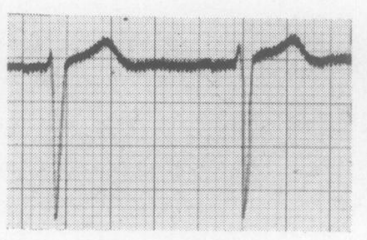

V I

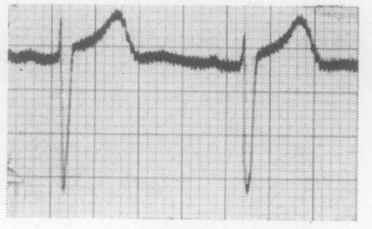

V 2

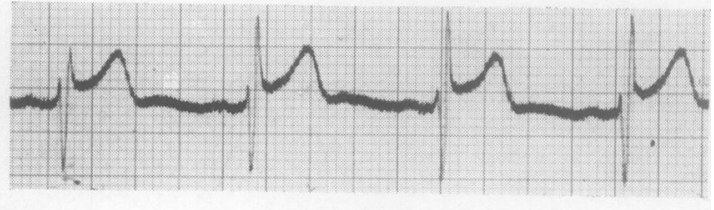

V 3

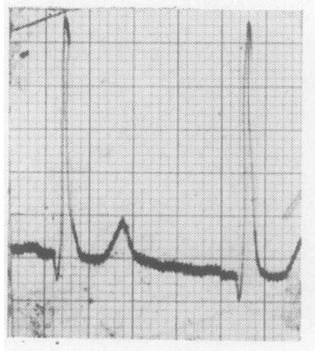

V 4

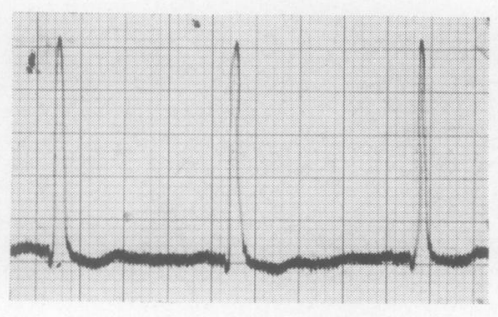

V 5

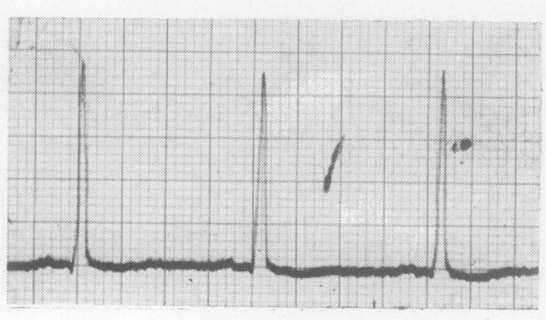

V 6

FIG. 5 (continued). 
In the last three cases in Group III there was no unanimity about the group to which the tracing belonged; further details are given in Fig. 6 (overleaf, pp. 118-120) and Table IX. In all three Observer A, at one or other of his assessments, expressed doubt as to the nature of the lesion; one of these, Case 160, was the only one in the entire series in which the particular abnormality first diagnosed by Observer $A_{1}$ failed to meet with agreement at any of the subsequent readings. The observers did not all agree that the tracings in Table IX were in fact abnormal, and they also disagreed in diagnosing Left Ventricular Hypertrophy or Myocardial Ischaemia. In Case 170 the possibility of Myocardial Infarction was raised by three observers.

\section{Frequency of the Various Diagnoses made by} EACH AsSESSOR

A summary of the diagnoses made at each assessment is given in Table $X$. In this survey Atrial Fibrillation without any obvious cause has been considered to be a consequence of coronary heart disease (Acheson and Acheson, 1958), as were the other four diagnoses listed in Table X. Observer D estimated the frequency of coronary heart disease on this basis to be 25 per cent.; the estimate at the other four assessments ranged from 34 per cent $\left(A_{1}\right)$ to 42 per cent. (C). The diagnosis of Left Ventricular Hypertrophy was made most frequently at four of the five assessments, the overall frequency ranging from 8 to 21 per cent.; Myocardial Ischaemia was the next most common diagnosis, the frequency varying from 2 to 9 per cent. It has been shown above that there was a good deal of difficulty in distinguishing between Left Ventricular Hypertrophy, Myocardial Ischaemia, and Myocardial
Infarction. Therefore it is a matter of some interest that, if the occasions when these diagnoses were made are added, the figures for each observer are $A_{1} 15, A_{2} 15, B 18, C 17$, and D 10; there is less variation in the frequency of the diagnoses when they are combined than when they were taken separately.

TABLe X

GROUPING AND DIAGNOSIS OF 53 ECGs AT FIVE INDEPENDENT ASSESSMENTS

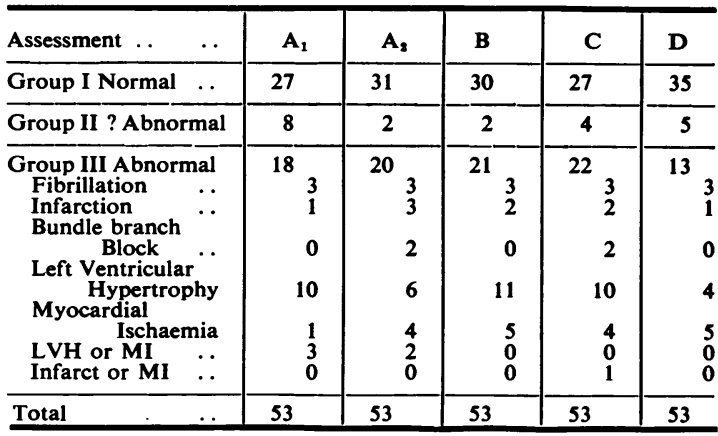

\section{Discussion}

The first matter which this investigation set out to examine was the observer error of Observer A on the first occasion he read the tracings. Before discussing his performance in detail it should be remembered that while Assessment $\mathbf{A}_{1}$ was made from the entire tracing, all other assessments were made from two or three complexes selected from each lead; thus the fact that the readings were not being made from identical material may contribute to some extent to observer error and variation. This unfortunate difference was unavoidable because the complete tracings were not considered sufficiently

TABLE IX

INTERPRETATIONS OF THREE GROUP III ECGS ABOUT WHICH THERE WAS SECOND DEGREE DISAGREEMENT (SEE FIG. 6)

\begin{tabular}{|c|c|c|c|c|c|c|c|c|}
\hline \multirow{2}{*}{ Case No. } & \multirow{2}{*}{ Age (yrs) } & \multicolumn{2}{|c|}{ Blood Pressure } & \multicolumn{5}{|c|}{ Interpretations of Observers } \\
\hline & & Systolic & Diastolic & $\mathbf{A}_{\mathbf{1}}$ & $\mathbf{A}_{2}$ & B & $\mathbf{C}$ & $\mathbf{D}$ \\
\hline 160 & 73 & 160 & 85 & $\begin{array}{l}\text { Left Ventricular } \\
\text { Hypertrophy } \\
\text { or } \\
\text { Myocardial } \\
\text { Ischaemia }\end{array}$ & $\begin{array}{l}\text { Incomplete } \\
\text { Right Bundle } \\
\text { Branch Block }\end{array}$ & Normal & $\begin{array}{l}\text { Incomplete } \\
\text { Right Bundle } \\
\text { Branch Block }\end{array}$ & Normal \\
\hline 170 & 72 & 195 & 95 & $\begin{array}{c}\text { Left Ventricular } \\
\text { Hypertrophy } \\
\text { or } \\
\text { Myocardial } \\
\text { Ischaemia } \\
\text { ? Infarct }\end{array}$ & $\begin{array}{l}\text { Old Anterior } \\
\text { Infarct }\end{array}$ & $\begin{array}{l}\text { Left Ventricular } \\
\text { Hypertrophy } \\
\text { ? Infarct }\end{array}$ & $\begin{array}{l}\text { Left Ventricular } \\
\text { Hypertrophy }\end{array}$ & Normal \\
\hline 172 & 76 & 140 & 90 & $\begin{array}{l}\text { Left Ventricular } \\
\text { Hypertrophy }\end{array}$ & $\begin{array}{c}\text { ? Ventricular } \\
\text { Hypertrophy } \\
\text { or } \\
\text { Myocardial } \\
\text { Ischaemia } \\
\text { ? Infarct }\end{array}$ & $\begin{array}{l}\text { Myocardial } \\
\text { Ischaemia }\end{array}$ & Normal & ? Myocardial \\
\hline
\end{tabular}


CASE 160

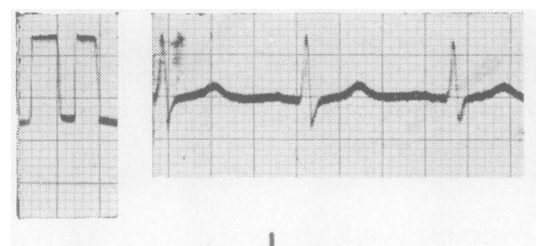

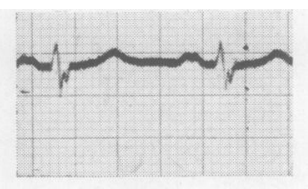

II

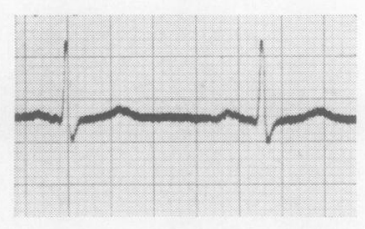

aVL

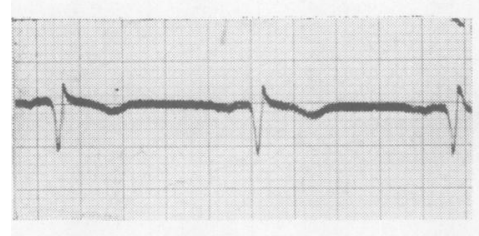

aVR

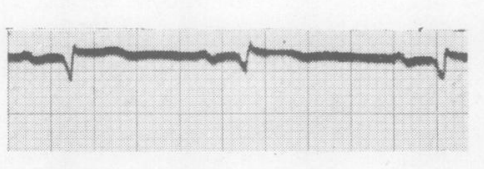

V I

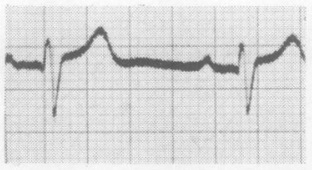

$\vee 2$

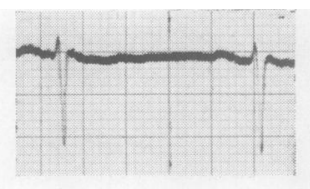

III

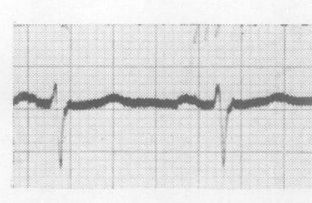

a V F

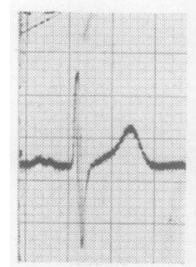

$\vee 4$

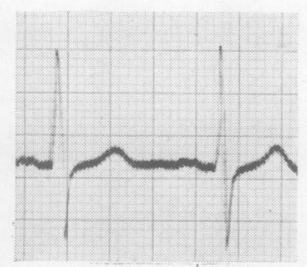

V 5

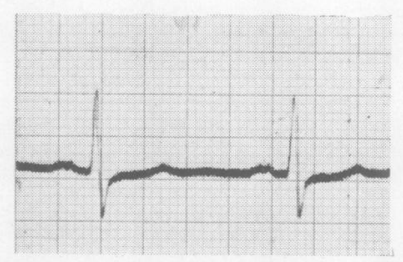

Vo

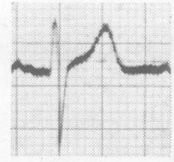

V 3

Fig. 6.-Three ECGs in Group III about which there was second degree disagreement in grouping (see also Table IX). 
CASE 170
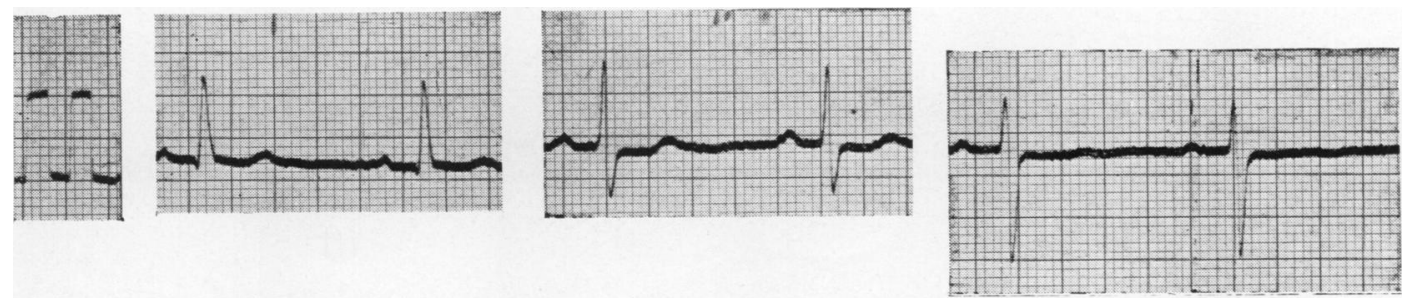

I

II

III

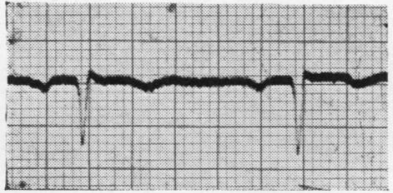

a VR

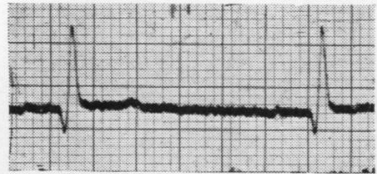

aVL

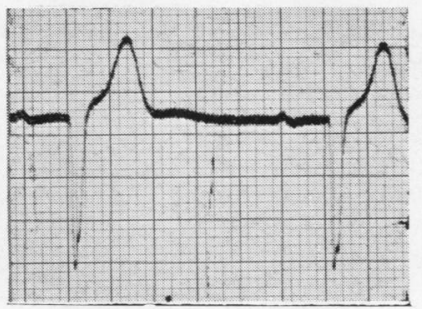

V 2

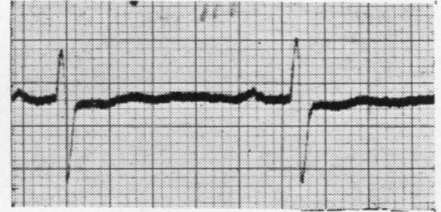

aVF

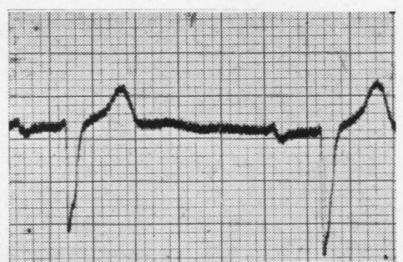

V I

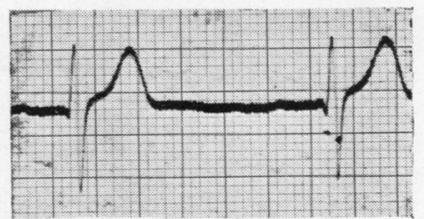

V 3
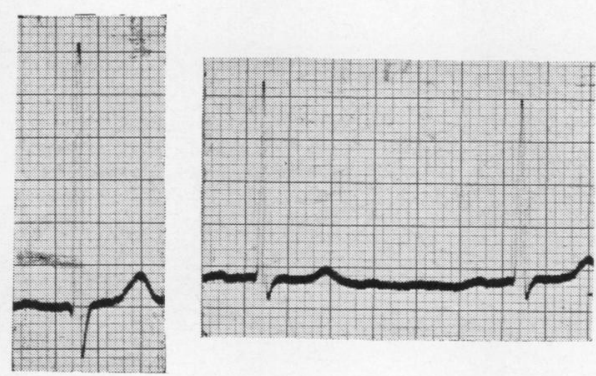

V4

V 5

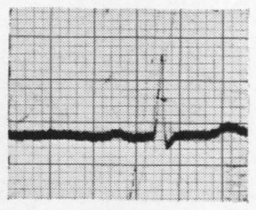

V 6

Fig. 6 (continued). 


\section{CASE 172}

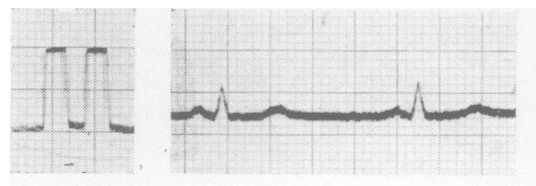

I

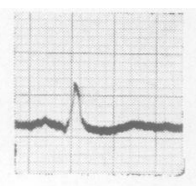

III

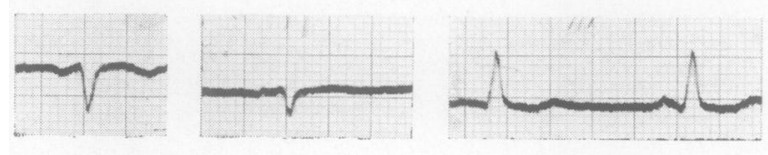

a VR

aVL

$a \vee F$

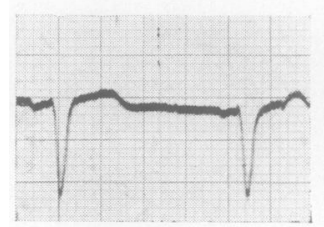

VI

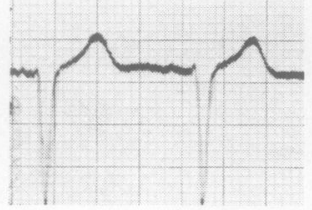

V 2

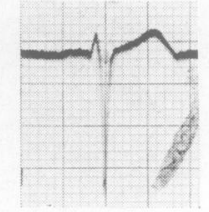

V3

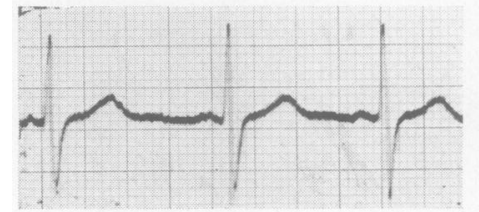

V4

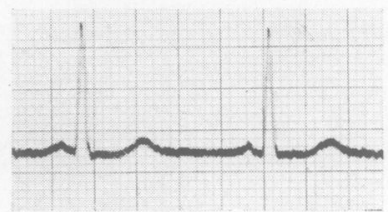

V 5

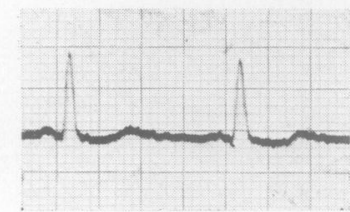

V 6

Fig. 6 (continued). 
robust to withstand the handling and many postal journeys which were necessary for the study. On the other hand it was not feasible-nor from the point of view of the survey as a whole desirable-to mount more than 220 ECGs, many of which included lengthy "after exercise" tracings. Two to three complexes are usually considered to be adequate when resting ECGs are being used in the epidemiology of coronary heart disease (W.H.O., 1959) but, as Table IV suggests, the effect of mounting the ECGs seems to have been to increase the number of second degree disagreements (and therefore the observer error) and to reduce the first degree disagreements (and therefore the observer variation). It seemed to make Observer A more positive in his classification of certain "difficult" ECGs, which, to judge from the difference of opinion they evoked among the other observers, did not warrant such positivity.

It has been indicated in the text that the ability of Observer A can be measured in various ways. Table IV shows that, as far as grouping is concerned, he agreed with himself on 83 per cent. of the tracings, and also that the other observers agreed with his assessment of the mounted tracings in 84 per cent. of their assessments. It is shown, too, that if the question of whether or not the ECGs were mounted is set aside, and Assessment $A_{1}$ is compared with all the rest, second degree disagreement arose on only seven out of 212 occasions, that is to say, on this criterion his error was 3 per cent.

The suggestion that the error of an individual observer might under any circumstances be as low as 3 per cent. would at first sight appear to be in contradiction to the conclusion drawn by Davies (1958), in a similar study, that no arbitrary line can be drawn between normal and abnormal tracings. This is not, however, the case for several reasons; first, Davies had nine skilled observers each of whom assessed each ECG twice, giving a total of eighteen assessments of each tracing, and dissent is more likely to be found among eighteen than among five. Therefore the difference between a level of unanimity in 32 out of 53 (60 per cent.) in the present study and of 29 per cent. in his is not so great as it seems.

Secondly, the assessors in the present study were told the blood pressure of the subject, whereas Davies (1958) gave no clinical information whatsoever. This item of information was included in this investigation because it is one of the few objective clinical procedures and so is unlikely to introduce any element of false bias. Since the present data were collected, Bronte-Stewart and Pickering (1959) and W.H.O. (1959) have stated that they consider the revelation of blood pressure reasonable when ECGs are being interpreted in studies such as this.

Finally, Davies insisted that each tracing should be placed emphatically in one of three categories of "normal", "Infarction", and "All Abnormalities Other than Infarction", whereas the observers in the present study were asked to arrive at a diagnosis, paying special attention to the presence or absence of coronary heart disease. When they were given their instructions they were not offered the opportunity of classing a tracing as "? abnormal", but they did, in fact, use such a classification to a greater or lesser extent, and no subsequent attempt was made to induce them to be more definite. Presumably, however, as has already been argued, if they had been coerced into placing the ECGs into two categories only, the observer error would have been increased, although the variation might have been reduced. This difference between the present analysis and that of Davies (1958) stemmed from the different intentions behind the two studies; whereas Davies set out to establish whether "unlike the chest film, electrocardiography is a test free from observer variation", the present purpose was primarily to examine the performance of an individual assessor.

Bearing these differences in mind, there can be no doubt that the present findings offer full support to the conclusion of Davies that "it is an illusion to believe there can be any arbitrary line between normal and abnormal tracings, or between abnormal and infarction tracings".

The sources of variation and error are more difficult to determine, and the most positive statement that can be made on the present evidence is that Atrial Fibrillation seems to bring about clearly distinguishable changes in the ECG because this diagnosis was offered by all the observers in three cases, but was never offered by any of them at any other time. Infarction was diagnosed definitely nine times and on a tenth occasion Observer $C$ could not decide whether the pattern of the tracing was due to Infarction or Ischaemia; five of these diagnoses were associated with a single tracing, giving an agreement level of 50 per cent. It also seems that there is a pattern which is acceptable as signifying Left Ventricular Hypertrophy, because there was unanimity about this diagnosis in four tracings-yet apart from these twenty occasions on which all the observers diagnosed Left Ventricular Hypertrophy there were a furthcr 21 occasions when it was diagnosed without universal agreement (agreement level 49 per cent.). In contrast, there was agreement about Myocardial Ischaemia in only five of the 
nineteen occasions ( 26 per cent.) on which it was definitely diagnosed; in the cases on which the observers disagreed whether the tracing was or was not Left Ventricular Hypertrophy, however, Myocardial Ischaemia was nearly always the second most popular diagnosis and vice versa. Thomas, Cochrane, and Higgins (1958) have also drawn attention to the difficulty experienced by independent observers in differentiating between these two diagnoses. Third on the list in this border-line group was Myocardial Infarction; W.H.O. (1959) suggested that "probable" Myocardial Infarction can be distinguished from "possible" Myocardial Infarction on the basis of changes in the Q-wave, but it was to the assessment of just these changes that Davies (1958) attributed most observer variation*. For these reasons, in the absence of aortic valvular lesions or some other contraindication, there would seem to be a strong argument in epidemiological studies of old men for grouping all cases where the tracing suggests Infarction, Left Ventricular Hypertrophy, or Myocardial Ischaemia together, and labelling them "Coronary Heart Disease", because in any age group coronary heart disease and hypertension are often found together. There is not the need in surveys for the precise diagnosis and prognosis which form the basis of sound clinical practice, and on the present evidence an attempt to subdivide the population whose ECGs show evidence of coronary or ischaemic lesions into smaller groups, will lead to spurious accuracy.

Finally, it appears that not only is there a continuum between the normal and the abnormal ECG, but there seem also to be continua between all the diagnoses offered by the assessors (except Fibrillation) and between each of these and normality (Fibrillation again excepted). Thus the case of Fletcher and Oldham (1959) and of Davies (1958) is strengthened in pressing for the recognition of the importance of observer variation by epidemiologists and clinicians alike.

\section{SUMmaRY}

56 electrocardiograms from a population sample of old men were chosen at random from a series of over 220; three were rejected as incomplete or imperfect, leaving a total of 53 for study. These ECGs were mounted on cards and assessed independently once by each of four observers, one of whom, Observer $\mathrm{A}$, had already interpreted the tracings before mounting and had also read all the other ECGs in the series. All four observers were clinical cardiologists, cardiological epidemiologists, or both, and they made a total of 265 assessments. The only

* See footnote t to p. 99 . clinical data they were given were age, blood pressure, and whether or not digitalis was being taken.

The principal assessor, Observer A, upheld his own opinion whether a tracing was "normal", "? abnormal", or "abnormal" in 83 per cent. if his second assessments. Similarly, his assessments of the mounted ECGs were upheld by the three other observers in 84 per cent. of 159 assessments. His own second assessment, and the assessments of the other three observers set the grouping error of his first assessment at 3 per cent.

The only diagnosis made with unanimity throughout was Atrial Fibrillation, about which there was 100 per cent. agreement in three cases, and which was not otherwise diagnosed. The complete agreement level for Myocardial Infarction was five out of the ten occasions on which the diagnosis was made (50 per cent.), for Left Ventricular Hypertrophy, twenty out of 41 (49 per cent.), and for Myocardial Ischaemia five out of nineteen ( 26 per cent.).

There were therefore many tracings which were unanimously agreed to be abnormal, but variously diagnosed as Left Ventricular Hypertrophy, Myocardial Ischaemia, or Myocardial Infarction.

Thus it may be concluded that, unless clinical examination reveals some lesion such as aortic valvular disease, which requires that they should be diagnosed otherwise, there is a case, in epidemiological studies of old men in whom two or three of these conditions may occur together, for grouping all such tracings as "Coronary Heart Disease".

My thanks are due to Dr. Donald Acheson, U.S. Veterans Administration, Washington; Dr. Ian Higgins, M.R.C. Pneumoconiosis Research Unit, Llandough, Glamorganshire; Dr. Grant Lee, Radcliffe Infirmary, Oxford, and Dr. A. J. Thomas, United Cardiff Hospitals, for their kindness in assessing the electrocardiograms. I am also most grateful to the directors and medical staff of Messrs. Arthur Guinness Son and Co. Ltd., Dublin, for making the survey possible, and to Prof. W. J. E. Jessop for his advice and encouragement. Prof. W. S. Walton kindly read the text.

\section{REFERENCES}

Acheson, R. M., and Acheson, E. D. (1958). Brit. J. prev. soc. Med. 12, 147 . Hemmens, W. F., and Jessop, W. J. (1958). Gerontologia (Basel), 2, 357.

Bronte-Stewart, B., and Pickering, G. W. (1959). In "Medical Surveys and Clinical Trials", ed. L. J. Witts, p. 253. Oxford University Press, London.

Davies, L. G. (1958). Brit. Heart J., 20, 153.

Fletcher, C. M., and Oldham, P. D. (1959). In "Medical Surveys and Clinical Trials", ed. L. J. Witts, p. 30. Oxford University Press, London. Thomas, A. J., Cochrane, A. L., and Higgins, I. T. T. (1958). Lancet,

World Health Organisation (1959). Techn. Rep. Ser., No. 168. W.H.O., Geneva. 